\title{
Chest Trauma at the Emergency Department of the Gabriel Touré University Hospital Bamako, Mali
}

\author{
Almeimoune Abdoulhamidou,2, Diop Madane Thierno1,2, Mangane Moustapha ${ }^{1,2}$, \\ Démbele Seidou Alaji ${ }^{2,3}$, Coulibaly Mahamadoun ${ }^{2,4}$, Sogoba Youssouf²,5, \\ Abdoulaye Chiad Mahamadoun Cisse ${ }^{2,6}$, Harouna Sangare1, Sidy Yattara1, \\ Ogalat Enyengue Murielle Ingrid1, Kassogue André1, Diallo Boubacar7, \\ Amadou Bah', Madiassa Konaté2,8, Yoro B. Sidibe', Diango Djibo Mahamane ${ }^{1,2}$ \\ ${ }^{1}$ Department of Anesthesia, Resuscitation and Emergency Medicine at CHU Gabriel Toure, Bamako, Mali \\ ${ }^{2}$ Bamako Faculty of Medicine and Odontostomatology, Bamako, Mali \\ ${ }^{3}$ Resuscitation Anesthesia Service CHU IOTA, Bamako, Mali \\ ${ }^{4}$ Anesthesia and Intensive Care Unit CHU Luxembourg, Bamako, Mali \\ ${ }^{5}$ Neurosurgery Department, The Gabriel Touré University Hospital, Bamako, Mali \\ ${ }^{6}$ Emergency Department, The Hospital of Mali, Bamako, Mali \\ ${ }^{7}$ Department of Anesthesia, Resuscitation and Emergency Medicine at CHU Point G, Bamako, Mali \\ ${ }^{8}$ General Surgery Department, The University Hospital of Gabriel Toure, Bamako, Mali \\ Email: abdoulhamidoumaiga@gmail.com
}

How to cite this paper: Abdoulhamidou, A., Thierno, D.M., Moustapha, M., Alaji, D.S., Mahamadoun, C., Youssouf, S., Cisse, A.C.M., Sangare, H., Yattara, S., Ingrid, O.E.M., André, K., Boubacar, D., Bah, A., Konaté, M., Sidibe, Y.B. and Mahamane, D.D. (2021) Chest Trauma at the Emergency Department of the Gabriel Touré University Hospital Bamako, Mali. Open Journal of Emergency Medicine, 9, 18-24. https://doi.org/10.4236/ojem.2021.92003

Received: March 10, 2021

Accepted: April 19, 2021

Published: April 22, 2021

Copyright (๑) 2021 by author(s) and Scientific Research Publishing Inc. This work is licensed under the Creative Commons Attribution International License (CC BY 4.0). http://creativecommons.org/licenses/by/4.0/

\begin{abstract}
In Mali, chest injuries remain a real public health problem and are associated with heavy morbidity and mortality. Faced with a resurgence of urban civil violence and the explosion of road accidents, we decided to conduct this study in order to describe the epidemiological, clinical and therapeutic aspects of thoracic trauma in the emergency department. Method and Material: This is a descriptive prospective study over a period of one year in the emergency department of the CHU Gabriel Touré. Including all patients admitted for thoracic trauma. Analysis and Entry: Data were entered and analyzed on SPSS software version 20.0. The test was significant for a $\mathrm{p}$ value $<$ 0.05. Results: We recorded 21,090 appeals in our structure among which 1284 patients were suspected of thoracic trauma. The diagnosis of thoracic trauma was retained in $119(0.56 \%)$ patients. All patients were transported to the emergency room without prehospital medicalization. Clinical presentation was dominated by dyspnea in $54.6 \%$ of patients, however pain was the almost constant symptom in conscious victims. Various traumatic mechanisms had caused these lesions of the thorax, of which road traffic accidents represented half of the causes, followed by urban civil violence in $28.6 \%$ of
\end{abstract}


patients. Landslides and falls from a great height were responsible for 19.5\% of chest injuries. Open chest trauma was the type of lesion found in a third of the cases. This type of injury was exclusively due to blows and injuries during the brawls. Standard chest radiography was performed as the first intention in $60 \%$ of patients compared to $10.9 \%$ for the pleuropulmonary ultrasound. Thirteen patients required ventilatory assistance after orotracheal intubation. The average length of stay was 65.23 hours. During the period of our study, the overall mortality was $1.85 \%$ in the emergency departments with a lethality specific to chest trauma of $15 \%$. Conclusion: Urban violence with its share of ballistic wounds determined the severity of this condition.

\section{Keywords}

Chest Trauma, Emergencies, Bamako, Mali

\section{Introduction}

Chest wall trauma is common. Approximately half a million patients presented to emergency departments in the United States in 2013 with an injury to their bony thorax, and about 200,000 of those were hospitalized [1]. Thoracic trauma is responsible for serious damage to the rib cage (costal flap) and or associated with severe pleural and parenchymal damage. Among all trauma wounds, hemopneumothorax is one of the most common, with a prevalence of $52.3 \%$, followed by hemothorax (23.4\%) and pneumothorax 20.7\%) [2] These severe injuries are clinically relevant to the multiple-injured patient as they affect respiratory mechanics, increasing the work of breathing and making it difficult for patients to effectively ventilate on their own. [3] They are the leading cause of traumatic death in children and young adults [4].

In Mali, chest trauma is a real public health problem and is associated with heavy morbidity and mortality [5] [6]. These high-velocity traumas largely explain their injury mechanism. Faced with a resurgence of urban civil violence, the explosion of road accidents, and the increase in gunshots and injuries, we decided to conduct this study in order to describe the epidemiological, clinical, and therapeutic aspects of thoracic trauma

\section{Method and Material}

\subsection{Type and Duration of Study}

This is a descriptive prospective study from October 1, 2018 to September 31, 2019, that is to say a period of 12 months. After reception and triage of casualties in the emergency room, cases of suspected chest trauma were followed up until inclusion in our study. In the patients included, the clinical, biological, radiological, sonographic and scannographic parameters were recorded all along with their stay in the emergency room. In patients who were difficult to mobilize for radiological and scannographic investigations, a pleuropulmonary ultrasound 
was systematically performed at the bedside. The patients included were followed until their discharge from the emergency room

This study included all the patients admitted to the emergency departments:

- Having an isolated thoracic trauma or in the context of multiple trauma.

- Chest wounds in the context of assault and battery.

- Chest pain following trauma unless computed tomography evidence to the contrary.

Patients with another etiology of non-traumatic chest pain were excluded.

Parameters studied: age, sex, prehospital medicalization, clinical signs, etiological mechanism, type of lesions, associated lesions, ventilatory assistance, therapeutic procedures, length of stay, mortality

\subsection{Study Framework}

This study took place in the emergency department of the Gabriel Touré university hospital. This hospital has the vocation of an emergency trauma hospital and mother-child emergency as such, it receives all forms of emergencies except medico-pediatric and obstetrical emergencies. The latter is received in dedicated reception areas separate from the emergency department.

The Emergency Department includes a sorting area, a two-bed removal room 02 short-term hospitalization units with 08 beds, 08 consultation boxes, an extendable sitting waiting area, 01 emergency operating room, 01 delocalized blood analysis laboratory, a radiology room, An administrative sector (02 offices and an amphitheater). During the period of this study, the operating room and the medical imaging department were closed for renovations.

\subsection{Analysis and Entry}

Data were entered and analyzed on SPSS software version 20.0. Text, tables and graphics were processed using Microsoft Office 2016 software: Word and Excel. The statistical tests used were Chi-square and Fischer's exact test. The test was significant for a $\mathrm{p}$ value $<0.05$.

\subsection{Ethical Consideration}

This study was carried out with the consent of the persons concerned and/or their families and the information collected remained confidential.

\section{Results}

At the end of our study, we recorded 21,090 recourse in our structure among which 1284 patients were suspected of thoracic trauma. The diagnosis of thoracic trauma was retained in 119 patients, that is to say an incidence of $0.56 \%$. The average age of the victims was 30.29 years with a sex ratio of 5.9. All patients were transported to the emergency room without prehospital medicalization first ambulance in $67.2 \%$ or in a personal vehicle $32.8 \%$. The clinical picture was dominated by dyspnea in $54.6 \%$ of patients, however pain was almost constant 
symptoms in conscious victims see (Figure 1). Various traumatic mechanisms had caused these lesions of the thorax, of which road traffic accidents represented half of the causes followed by urban civil violence in $28.6 \%$ of patients. Landslides and falls from a great height were responsible for $19.5 \%$ of chest injuries. In our context, landslides are mainly due to traditional gold mining. Open chest trauma was the type of lesion found in a third of the cases. This type of injury was exclusively due to blows and injuries during the brawls. These injuries were inflicted by bladed weapons in two-thirds of cases against onethird for firearms. The ballistic attacks were particularly formidable and for good reason, Figure 2 shows a ballistic impact in the precordial area. The patient in question presented with a very abundant hemothorax. The extremely urgent chest tube was clamped due to the amount of bleeding and the added state of shock. He was rushed to the operating room where thoracomy and hemostasis revealed a pericardial and right hilar vascular lesion. The standard chest x-ray was performed as a first-line examination in $60 \%$ of patients against $10.9 \%$ for pleuropulmonary ultrasound it should be noted that the thoraco-abdominal and cerebral CT scan were performed respectively in $55.5 \%$ and $26.9 \%$ of patients. Bone lesions of the thoracic case were found in half of the patients. Seventyfour percent of the patients had pleural lesions, including 41.2\% Pneumothorax and $32.8 \%$ pneumothorax. Half of these thoracic traumas were in the context of

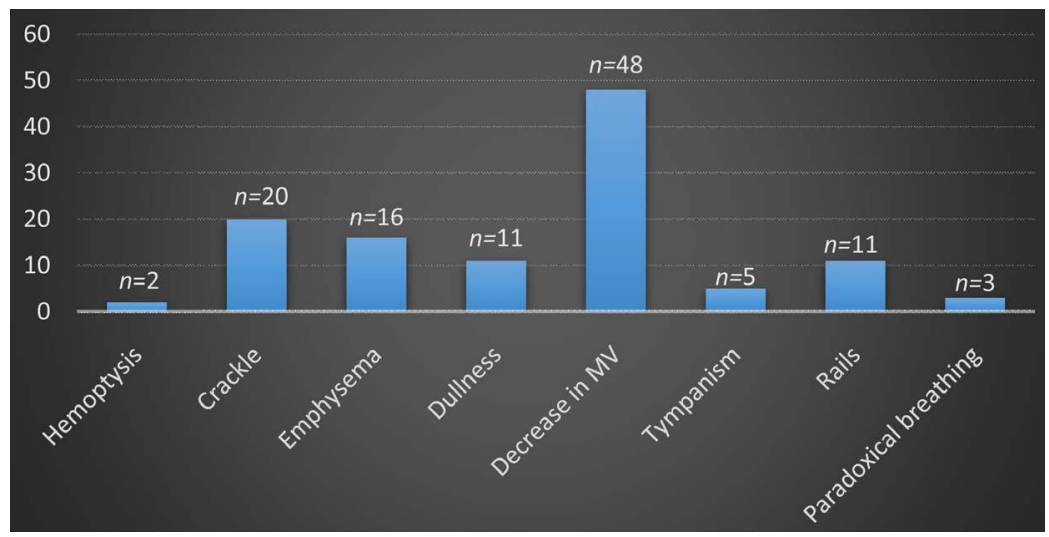

Figure 1. Initial clinical signs.

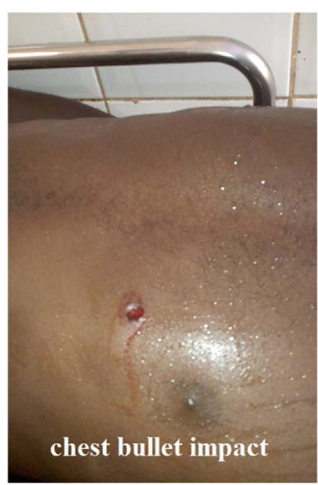

Figure 2. Chest bullet impact. 
multiple trauma. Head trauma was the most associated lesion found in a third of our patients. Bone lesions of the thoracic case were found in half of the patients. Seventy-four percent of the patients had pleural lesions, including $41.2 \%$ Pneumothorax and 32.8\% pneumothorax. Half of these thoracic traumas were in the context of multiple trauma. Head trauma was the most associated lesion found in a third of our patients. Fifty-three patients had received oxygen therapy because they were unable to maintain artificial oxygen saturation greater than $90 \%$ in ambulatory air, this hypoxemia was also the main criterion of severity recorded [6]. Thirteen patients required ventilatory assistance after orotracheal intubation. After initial management, a third of patients were referred to the thoracic surgery department of another hospital. The average length of stay was 65.23 hours. During the period of our study, the overall mortality was $1.85 \%$ in the emergency departments with a lethality specific to chest trauma of $15 \%$.

\section{Comments and Discussion}

One of the major limitations of our study was the non-feasibility of the thoracic scanner in our hospital (imaging department closed for work), this situation considerably delayed the treatment options and was a loss of opportunity for the most serious patients. The aetiologies, the injury mechanisms, the types of injuries, the mode of transport of the victims, the socio-demographic profile of the victims present great similarities in black Africa over the last five years [7] [8] [9]. In our countries with limited resources, pre-hospital mortality is such that certain lesions (wounds of the heart and large vessels) described in the literature [10] are rarely encountered in emergencies for lack of an emergency system and efficient pre-hospital medicine. Chest wounds from firearms lead to fear of the most dreaded lesions, especially when the point of impact is in the precordial area (Figure 2). Despite a large proportion of patients with dyspnea, only in 13 patients (10.9\%) we had recourse to invasive ventilation. According to the recommendations of the SFAR and the SFMU [6] in hospitals, non-invasive ventilation (NIV) of the spontaneous ventilation type with inspiratory support and positive expiratory pressure must be delivered. It must be recognized that in emergency medicine the application of this recommendation is difficult because it consumes time and resources, raises the difficulty of adaptability of the VNI interface and the requirement of an environment with continuous monitoring. In our study, the main argument that prevailed in the choice of invasive ventilation was the considerable incidence of associated injuries, especially head trauma. The standard chest $\mathrm{x}$-ray on the patient's bed remains a key diagnostic tool for eliminating a pleural lesion, especially a suffocating pneumothorax in the trauma patient of the chest (Figure 3), however pleuropulmonary ultrasound is a practical alternative to emergencies because it is easy to teach and perform. It has the advantage of being accessible without moving the patient, of being repetitive without ionizing radiation. Pleuropulmonary ultrasound, completely absent from our practice two years ago, allowed us to establish the diagnosis of pleural effusion in $11 \%$ of our patients in the emergency room. 


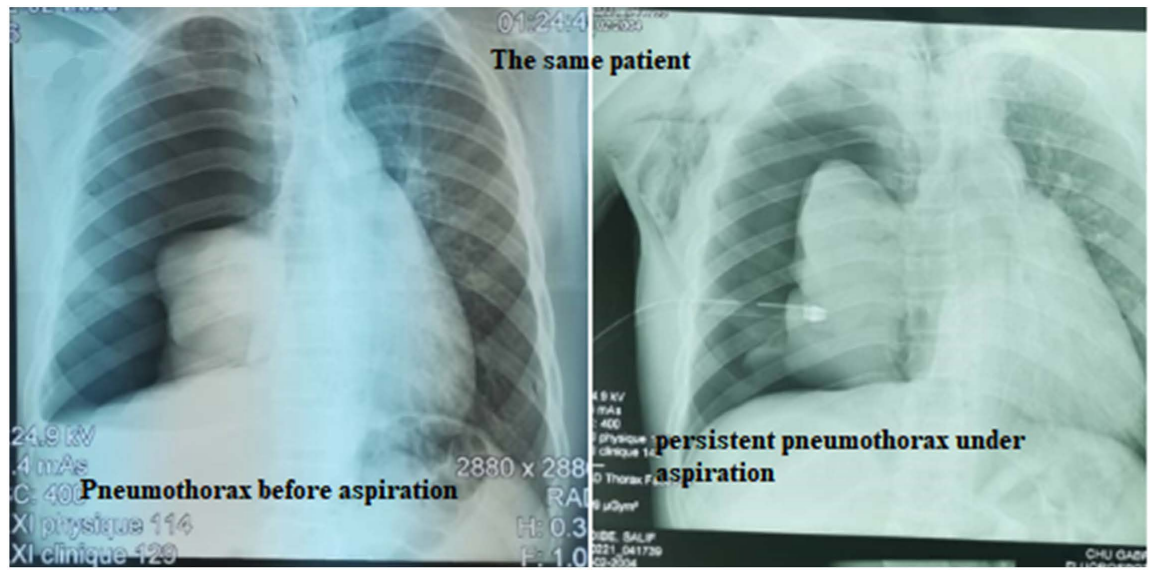

Figure 3. X-ray of a patient with pneumothorax.

\section{Conclusion}

Despite a context of prehospital medical misery and precariousness of paraclinical hospital investigation, the speed of the care and the multidisciplinary approach was a major asset to the survival of the victims.

\section{Conflicts of Interest}

The authors declare no conflicts of interest regarding the publication of this paper.

\section{References}

[1] Majercik, S. and Pieracci, F.M. (2017) Chest Wall Trauma. Thoracic Surgery Clinics, 27, 113-121. https://doi.org/10.1016/j.thorsurg.2017.01.004

[2] Morales, C.H., Mejía, C., Roldan, L.A., Saldarriaga, M.F. and Duque, A.F. (2014) Negative Pleural Suction in Thoracic Trauma Patients: A randomized Controlled Trial. Journal of Trauma and Acute Care Surgery, 77, 251-255. https://doi.org/10.1097/TA.0000000000000281

[3] Swart, E., Laratta, J., Slobogean, G. and Mehta, S. (2017) Operative Treatment of Rib Fractures in Flail Chest Injuries: A Meta-analysis and Cost-Effectiveness Analysis. Journal of Orthopaedic Trauma, 31, 64-70. https://doi.org/10.1097/BOT.0000000000000750

[4] Adnet, F. (2003) Prise en charge d'un traumatisme thoracique sans signe évident de gravité. In Séminaire S.F.M.U.

https://www.sfmu.org/upload/70_formation/02_eformation/03_journees/archives/a dnet.pdf

[5] Yena, S., Sanogo, Z.Z., Sangaré, D., Keita, A.D., Coulibaly, Y., Ouattara, M., Koita, A., et al. (2006) Traumatismes thoraciques à l'hôpital du point G. Mali Médical, 21, 43-48.

[6] Carrié, C. and Biais, M. (2021) Prise en charge du traumatisme thoracique en 2020. Anesthésie \& Réanimation, 7, 125-133. https://doi.org/10.1016/j.anrea.2021.02.004 WWW.em-consulte.com/revue/anrea www.sciencedirect.com

[7] Niang, E.H.M., Bona, D.O., Diallo, A., et al. (2017) Prise en charge du traumatisme thoracique à la réanimation de l'hôpital principal de Dakar/Sénégal. Rev. Afr. Anesthésiol. Med. Urgence, 22, 47-52.

https://web-saraf.net/IMG/pdf/t22_v1_47_52_niang_e.pdf 
[8] Bah, M.L., Camara, A.K., Bah, A.A., et al. (2017) Traumatisme fermé du thorax: Aspect épidémiologique prise en charge au CHU de Conakry. Revint sc méd-RISM, 19, 52-56. http://www.revues-ufhb-ci.org/?parcours=revues\&desc $=5 \& \operatorname{arti}=827$

[9] Rajaonera, A.T., Razafimanjato, N.N.M., Raoelijaona, L.H., et al. (2016) Traumatismes thoraciques: Un défi de prise en charge en réanimation. Batna Journal of Medical Sciences, 3, 108-111.

[10] Avaro, J.P., Djourno, X.B., Trousse, D., et al. (2006) Le traumatisme thoracique grave aux urgences, stratégie de prise en charge initiale. Réanimation, 15, 561-567. https://doi.org/10.1016/j.reaurg.2006.10.010 